\title{
Faculty Learning and Professional Growth in the Sabbatical Leave
}

\author{
Susan K. Gardner ${ }^{1}$ (1)
}

Accepted: 13 October 2021 / Published online: 23 October 2021

(C) The Author(s), under exclusive licence to Springer Nature B.V. 2021

\begin{abstract}
The faculty sabbatical leave has been present in many institutions of higher education since its inception at Harvard University in 1880 but is relatively underexamined in the literature related to the outcomes not only to the institution but also to the faculty member. This study included interviews with 12 faculty members at one research university in the U.S. to better understand their perceptions of their sabbatical experiences in relation to the model of faculty professional growth. Findings underscored that faculty were agentic in their learning, the professional relationships they sought out to do this learning, as well as the commitments they made in this learning and growth, including that of their own work-life balance.
\end{abstract}

Keywords Faculty sabbatical $\cdot$ Learning $\cdot$ Professional growth

Research on the role of learning in faculty members' lives is critical because the success of faculty members' learning experiences has real consequences for students, scholarly communities, and the larger society that is informed by their work. If learning is a prerequisite to teaching, research, and service, then higher education researchers and practitioners would be wise to understand the factors and contexts that promote and sustain faculty learning. (Lattuca, 2005, p. 14)

Beginning at Harvard University in 1880 (Eells, 1962; Sima, 2000), the sabbatical leave has become a common experience for many full-time faculty throughout the United States. Drawing from the literature, the purpose of the academic sabbatical generally falls within one of five areas: (a) scholarly enrichment, (b) teaching improvement, (c) curricular development, and (d) creative growth, and (e) an opportunity to consider new directions in one's work (Eberle \& Thompson, 1972; Eells, 1962; Kang \& Miller, 1999; Sima, 2000; Zahorski, 1994). Despite its long history at U.S. institutions of higher education, relatively little research has examined the sabbatical or the faculty's perceptions of it. Instead, a common refrain in the scant

Susan K. Gardner

1 Oregon State University, Corvallis, OR 97331, USA 
literature about the sabbatical has been a focus on measures of faculty productivity and the need for accountability from the sabbatical (Miller et al., 2012; Sima, 2000). This demand for accountability stems from a desire to demonstrate the public good that emanates from this faculty leave time. Studies that have demonstrated faculty scholarly production - or the lack thereof (Mamiseishvili \& Miller, 2010; Sima \& Denton, 1995) - are common, therefore, in the literature about faculty sabbatical leaves but tend to omit the other positive benefits that result from this experience.

Namely, in this article I contend that the sabbatical leave provides a concentrated opportunity by which the faculty member may engage in learning. This learning, which is part and parcel of the faculty member's training and profession (Gappa et al., 2007; Neumann, 2009; O'Meara et al., 2017), is unfortunately rarely discussed (Lattuca, 2005); yet, faculty learning has been shown to play a key role in job satisfaction and faculty retention (O'Meara et al., 2017).

The purpose of this study was to understand the perceptions of faculty members related to their sabbatical experiences at one research institution though the lens of faculty learning and professional growth. I begin with an overview of the literature related to the faculty sabbatical along with a discussion of the conceptual lens of faculty learning and faculty professional growth. The methods I used to conduct the study as well as the findings then follow. I conclude with a discussion of the findings in relation to the literature as well as in connection with policy, practice, and future research.

\section{The Sabbatical: a Review of the Literature}

Since its inception in the United States, the purpose of the faculty sabbatical leave has been somewhat unclear. Originating from the ancient Hebrew word sabbath and the biblical day of rest (Kang \& Miller, 1999; Kimball, 1978), sabbaticals are generally granted after the sixth year of the faculty career at either a half year with full pay or a full year with half pay (Eberle \& Thompson, 1972; Eells, 1962; Kang \& Miller, 1999; Kimball, 1978). While typically considered a benefit for full-time faculty at many research-oriented institutions, faculty sabbaticals have long been in place across all institutional types, including community colleges (Academic Senate for California Community Colleges, 2007; Eells \& Hollis, 1962; Schuster \& Finkelstein, 2006). In what may be the most recent national data collected on the offering of faculty sabbaticals, the 1992 edition of the Digest of Education Statistics reported nearly $74 \%$ of all 2-year and 4-year institutions in the United States offered sabbaticals (as cited in Kang \& Miller, 1999). Most often associated as a benefit granted after an assistant professor earns tenure and promotion, sabbaticals have also been documented as occurring throughout the faculty career (Zahorski, 1994). At the same time, sabbaticals have often found to be on the budgetary chopping block in tough financial times (AAUP, 2009) as they tend to be seen as expensive benefits to offer. At the same time, many institutions' financial support of the sabbatical can vary, wherein institutions tend to only partially fund the salary of the faculty member, resulting in cost savings for institutions who tend to hire much less costly contingent faculty to replace them (Otto \& Kroth, 2011). The irony of this, of course, is 
that as institutions continue to face financial challenges, more contingent faculty are hired to replace these full-time faculty members (AAUP, 2009) and these contingent faculty are not known to be provided with sabbatical leaves.

Regardless of context, though, colleges and universities offering their full-time faculty members a sabbatical leave have been clear that it is intended to be a time of doing rather than resting. For some institutions, the sabbatical has been seen as an investment in itself or its future capacity (American Association of University Professors, 1995; Eells \& Hollis, 1962; Kimball, 1978; Marsh \& Hattie, 2002; Rosser, 2004) and not necessarily an investment in the individual faculty member, with some even questioning the value of the sabbatical altogether (Mamiseishvili \& Miller, 2010; Sima \& Denton, 1995). Others have seen the sabbatical as a mutual benefit to the faculty member and the institution (Eells, 1962; Miller et al., 2012; Rosser, 2004), including Columbia University, which in 1907 stated the purpose of its sabbatical was "for the good of university education...for the real University teacher an intellectual and practical necessity" (as cited in Eells, 1962, p. 253).

Indeed, the purposes espoused in the existing literature underscore the mutuality of benefits emanating from the sabbatical. Sima and Denton (1995) summarized the purposes as such: (a) to conduct research; (b) to engage in uninterrupted study; (c) to write journal articles or a book; (d) to enhance artistic performance and creative growth; (e) to improve teaching; (f) to promote course and curriculum development; (g) for refreshment, new experience and travel; and (h) to complete graduate work. From this perspective, the activities and products in which a faculty member engages during the sabbatical leave provide not only professional development and enrichment for the faculty member but also products, outcomes, and long-term effects for the higher education institution in which the faculty member is employed. Interestingly, despite the long history of faculty sabbaticals, as well as the multiple institutional types at which they have been offered, relatively little empirical research exists about them, faculty experiences with them, or the outcomes that emanate from them. The sparse research on the faculty sabbatical that does exist is characterized by a focus on outcomes that are predominantly tangible in nature; meaning, a focus on the output of articles, grant applications and grant dollars, as well as other countable outcomes (Davidson et al., 2010; Mamiseishvili \& Miller, 2010; Sima, 2000; Sima \& Denton, 1995). Outcomes that are more personal to the faculty member, such as rest, refreshment, and rejuvenation (Sima \& Denton, 1995), are much less visible in the empirical literature and instead more prevalent in anecdotal accounts (Baruch et al., 2014). Of course, metrics are easy to account for but mask the less tangible outcomes that also emanate from the faculty sabbatical, including that of learning and professional growth.

\section{Faculty Learning and Professional Growth}

It would not be an overstatement to say that the study of faculty and their careers has become commonplace in the academic literature. Faculty outcomes, experiences, preparation, and career progression have become a hallmark of this literature (e.g., Austin, 2002; Baldwin \& Blackburn, 1981; Blackburn \& Lawrence, 1995; Gardner 
\& Blackstone, 2013; Gonzales, 2014; Hagedorn, 2000; Wolf-Wendel \& Ward, 2006; $\mathrm{Xu}, 2008$; Zhou \& Volkwein, 2004). Only until recently, however, has the focus on faculty learning also become a part of this literature.

Certainly, faculty do not stop learning once they have earned their degrees but continue to learn as their careers progress, in both personal and professional ways (Lattuca, 2005; Neumann, 2005, 2009). One might envision professional learning as encompassing many kinds of learning for the faculty member, related to the various aspects of their professional lives. Of interest in the current study is what O'Meara et al. (2017) referred to as faculty scholarly learning or learning that is "occurring when faculty members increase subject matter knowledge and skills" (p. 356).

Faculty scholarly learning is therefore associated with the faculty member's personal and professional interests (Hermanowicz, 1998) as well as their ability to further their knowledge and understanding of their content areas (O'Meara et al. 2017). Learning, in this way, is most often self-directed but scholarly learning is also evidenced in collaborative work (Lattuca, 2005), including that of interdisciplinary collaboration (Gardner et al., 2014; Lattuca, 2001). Thus, learning becomes the center of the faculty career (O'Meara et al. 2017).

Learning does not happen in a vacuum, of course. As O'Meara et al. (2017) have forwarded, learning is influenced by institutional structures, processes, and cultures; namely, supportive work cultures that unite faculty colleagues as well as provide resources to engage in thinking and learning. In this way, the faculty sabbatical leave becomes an apt example of such a supportive structure.

One way to encapsulate that various aspects of faculty learning is through the lens of faculty professional growth, or "change that allows professionals to bring new and diverse knowledge, skills, values, and professional orientation to their work" (O’Meara \& Terosky, 2010, p. 45). Built upon earlier conceptualizations of adult learning and adult development (Merriam, 2001) as well as human development (Erikson, 1980), faculty professional growth - or FPG - encompasses four key aspects: (a) learning, (b) agency, (c) professional relationships, and (d) commitments.

The first component of the FPG model is that of learning. Faculty are expert learners (Neumann, 2009; O’Meara et al., 2008). "Faculty carry out their learning in their many different work roles (teaching, research, internal service, and outreach), in different ways with different groups (students, colleagues, the public), and in different organizational contexts (institutional or appointment type)" (O'Meara et al. 2008, p. 26).

Related to the second aspect of FPG - agency - O'Meara et al. (2008) described it as the desire of the individual faculty member to "construct the contexts" of their learning and development in professional and intellectual ways (p. 28). Faculty agency, in this way, helps to shape the kind of learning in which the faculty members wishes to engage, and is "critical in navigating workplaces and composing meaningful careers" (p. 29). Agency allows the faculty member to decide what kinds of learning are most meaningful to them, which at times may result in taking intellectual risks, or in deciding to choose life balance over their professional experiences (O'Meara et al. 2008). Agency is particularly important when a faculty member engages in purposeful decision-making about the work they will take up 
in their careers, particularly in light of which kinds of work tend to be rewarded or diminished in the academy (Baez, 2000; Gonzales, 2014).

The third element of the FPG framework is that of professional relationships or "interactions that provide personal and professional support; that stimulate, facilitate, and shape learning; and that strengthen faculty capacity to bring the best of their talents to their work roles" (O'Meara et al. 2008, p. 29) or what Neumann (2009) referred to as colleagueship. Such professional relationships can be experienced in teaching, scholarship, or service duties on the part of the faculty member.

The final element of the FPG framework is commitments or "long-term, conscious, personal, and professional investments that scholars make in certain people, programs, places, and social concerns through concrete activity that furthers the goals of higher education" (O'Meara et al. 2008, pp. 30-31). One might consider commitments in the FPG model including deliberate action on the part of the faculty member to engage in teaching, scholarship, community engagement, and institutional governance in ways that are meaningful to them.

Akin to their explanation of faculty learning (O'Meara et al., 2017), O'Meara and colleagues (2008) forwarded that supportive environments and supportive structures facilitate faculty professional growth. Indeed, when such supportive environments exist, faculty members have reported higher agency to achieve career goals (O'Meara et al., 2017), along with higher job satisfaction and retention (O'Meara et al., 2017). At the same time, specific opportunities for faculty professional growth may or may not be created by the institution at which the faculty member works but faculty professional growth is always rooted in self-directed or agentic actions on the part of the faculty member (Lattuca, 2005; O'Meara et al., 2008).

Despite the ubiquity of learning and professional growth in the faculty career, relatively sparse literature exists about it or faculty experiences of it. One reason for the paucity of the literature may owe to the fact that such learning is difficult to document when compared to easily quantified products such as publications or grants (Lattuca, 2002). Faculty sabbatical experiences have received similar short shrift in the empirical literature focusing generally on quantifiable outcomes rather than less measurable outcomes. Therefore, I chose to utilize the framework of faculty professional growth as a way to best understand the less tangible outcomes of the faculty sabbatical through the lived experiences of faculty members at one institution during their sabbatical leaves, thereby addressing this gap in the literature about both faculty learning and the faculty sabbatical.

\section{Methods}

The guiding research questions for this study were:

(1) What were the sabbatical experiences of faculty members at one research institution?

(2) How do faculty members perceive the learning and professional growth they experienced during their sabbatical leave? and

(3) How do faculty exercise agency in designing their sabbatical leave? 
The study was qualitative in nature, encompassing in-depth interviews with 12 faculty members at one research university in the United States.

The qualitative design of this study was chosen for two main reasons. First, the sabbatical experience and the literature and research related to it are sparse. Many qualitative studies are heuristic in nature, providing an opportunity to "bring about the discovery of new meaning [and to] extend the reader's experience" (Merriam, 2009 , p. 44) while also exploring the widest range of experiences within that context (Merriam, 2009).

Second, a qualitative design is helpful when the context is bound to the knowledge sought from the participants (Merriam, 2009). In this study, the context was one specific institution of higher education as its culture was vital for understanding the faculty members' experiences. The institution examined is a public, mid-sized university, labeled by the Carnegie Classification (2018) as a Doctoral University with High Research Activity - also known as an R2 institution. Located in a rural part of the United States, the institution - hereafter referred to as Land Grant University - reflects its predominately white setting with a faculty make up very similar to its state's population.

The faculty members at Land Grant University are unionized and their sabbatical leaves are part of the faculty contract for the larger university system in which LGU is situated. Per the contract, up to 25 sabbaticals are provided to the LGU campus each year, with full pay for one semester and half pay for a full year. Faculty under this contract are provided with sabbatical benefits after six years of full-time service, except for faculty at the rank of "full" professor who are eligible every five years. Faculty must return to LGU after their sabbatical for one academic year or be required to pay back the salary. In other words, the expectations and norms at LGU related to the faculty sabbatical are consistent with the literature (Eells \& Hollis, 1962; Kang \& Miller, 1999; Miller et al., 2012; Zahorski, 1994).

The faculty members included in the study were 12 tenured faculty members. All of these faculty members had experienced at least one sabbatical leave during their time at the institution, with half of the participants having experienced two sabbatical leaves. All of the faculty members' sabbaticals occurred between the years of 2006 and 2020, with several of the participants having taken their sabbatical leaves in $2018(N=4)$ and $2019(N=4)$. Eleven of the 12 faculty members were in research-based faculty roles, wherein their appointments expected research output on top of their teaching responsibilities. The other faculty member was in a teaching-focused unit that did not have heavy research expectations. In other words, the majority of the faculty members were research producers at LGU, with all of them receiving awards, grant dollars, and media to recognize their research. Therefore, as a qualitative design, the participants reflected what Yin (2009) referred to as representative or typical cases of the context under examination.

Five faculty members represented the social sciences, two from the humanities, two from the professional fields, and three from STEM fields. The gender and racial identities of the faculty members generally reflected the larger faculty of the institution in that 1 of the 12 (or 8\%) participants identified as a faculty member of color and exactly half (50\%) identified as women and the other half as men. Table 1 provides an overview of the participants' demographics, including pseudonyms 
Table 1 Participant demographics

\begin{tabular}{llllll}
\hline Pseudonym & Disciplinary Area & Rank & Gender & Years at LGU & $\begin{array}{l}\text { Total } \\
\text { Sabbati- } \\
\text { cals }\end{array}$ \\
\hline Sadie & Social Sciences & Associate & Woman & 15 & 1 \\
Adia & Humanities & Associate & Woman & 26 & 2 \\
Ashley & Humanities & Professor & Woman & 14 & 2 \\
Felicia & Professional & Professor & Woman & 13 & 1 \\
Claire & Social Sciences & Professor & Woman & 14 & 2 \\
Julie & STEM & Associate & Woman & 12 & 1 \\
George & Social Sciences & Associate & Man & 18 & 1 \\
Gordon & Social Sciences & Associate & Man & 9 & 1 \\
Jeremy & Social Sciences & Associate & Man & 14 & 2 \\
Ben & Professional & Professor & Man & 15 & 2 \\
Dan & STEM & Associate & Man & 32 & 1 \\
Zach & STEM & Professor & Man & 19 & 2 \\
\hline
\end{tabular}

assigned to protect their identities as well as general disciplinary areas. Due to the small number of faculty of color at LGU, race is omitted from the table's demographics.

The 12 participants were recruited from an email sent to all associate and "full" professors $(N=190)$ in the spring of 2020. These 190 individuals were considered the full study population as they had been eligible for at least one sabbatical as associate professors and at least two sabbaticals as professors, following the terms of the union contract. In this recruitment email, I also stated that I sought participants who had a copy of their final sabbatical report to share, which was another requirement of the institution's sabbatical policy. Ultimately, 22 faculty members responded to the email solicitation but only 12 indicated that they had a copy of their sabbatical report. These 12 individuals were therefore selected to move forward as participants in this study, although I ultimately chose to omit the analysis of the sabbatical report as a data point due to the lack of uneven application of this policy.

Finally, it is important to note that all of the interviews for this study were completed during the spring and summer months of 2020, during the COVID-19 pandemic. Due to budgetary concerns related to declining enrollments and state funding shortfalls, Land Grant University was facing a difficult budgetary outlook. At the same time, Land Grant University was perennially in such a situation, as decades of declining state support had become commonplace. Such financial straits often resulted in dire budgeting forecasts, including the announcement of possible cuts to beloved programs and resources. In the spring of 2020, one idea that was proffered to meet the budgetary shortfall was the possible removal of faculty sabbaticals; hence, the genesis of this study.

After obtaining their informed consent, interviews with the 12 faculty members were conducted via Zoom, lasting from 45-90 min, using a semi-structured protocol. The 12-question protocol focused upon timing and duration of the faculty members' 
sabbaticals as well as their motivation to take a sabbatical, their anticipated plans for the sabbatical and actual outcomes. As it was an exploratory study, the protocol was open-ended in nature to provide for a truly emergent set of themes to evolve. Even with such an open-ended protocol, saturation of data was evident from these interviews in that faculty members shared similar perspectives and outcomes from their sabbatical experiences. Interviews were transcribed verbatim and analyzed using the process as described by Merriam (2009). First, I conducted open coding, utilizing field notes and transcripts. As I continued to transcribe and analyze the transcripts, a series of categories inductively emerged. From these categories, I then utilized the process of axial coding, which further refined my analysis. At this point, I condensed the many categories and codes that had been generated from analysis into a smaller number of themes. These themes were then examined using the concepts embodied by faculty learning and faculty professional growth (O'Meara et al., 2008, 2017). Trustworthiness was obtained as I utilized member checking, where a bulleted list of general ideas and themes that emerged from each interview was sent to each participant for verification and validation.

As an additional measure of trustworthiness, I closely examined my own positionality in relation to this study and reflected on my assumptions and biases through my field notes during the data collection and analysis process. As a full-time, tenured faculty member employed at a research university who has experienced only one sabbatical, my perspective, privilege, and lenses were certainly brought to bear on this study, its design, as well as the interpretation of the data.

\section{Findings}

The concepts of learning and its connection to faculty professional growth were endemic in the 12 faculty members' discussions of their sabbatical experiences. In the following section, I detail the contours of faculty learning and their professional growth that resulted from their sabbatical experiences, using the model of O'Meara and colleagues (O'Meara et al., 2008) to frame the findings.

\section{Learning}

The first part of O'Meara et al.'s (2008) model of faculty professional growth encompasses learning. While 8 of the 12 participants explicitly used the term learning in their descriptions of their sabbatical experiences, learning was implicitly present in all participants' experiences. Indeed, learning was the most prevalent aspect of the faculty members' descriptions of their sabbatical time. What was interesting was that this learning encompassed all areas of the faculty role, including research, teaching, and service.

All of the faculty members discussed how the sabbatical leave provided them with time and space to focus on their learning. This space and time to learn was mentioned in ways such as "stepping away," "time to think," "to gain perspective," and even "productive boredom." Jeremy shared, "The sabbatical is like a training 
period in which you can prioritize new avenues of research and think about your work more creatively." Julie agreed, "It's just uninterrupted time to think about something new and a time where I could just focus on thinking about my research."

Some of the faculty members talked about structured learning opportunities in which they engaged in courses, participated in seminars, or even enrolled in academic programs. Gordon stated, "I spent a lot of my sabbatical working on teaching. I took classes as a student, in part, because I wanted to remember what it's like to be a student and, boy, was that more useful even than I thought it was going to be." Felicia enrolled in a training program focused on media during her sabbatical and shared, "I love learning so much and, for me, it was a chance to just really be immersed in my own education." Ashley, too, gained a lot of perspective about her teaching during her sabbatical by learning:

I was reading and thinking and all these different directions that radically changed the way I taught and gave back to me pedagogically. It matters a lot to me that I keep reading and keep thinking and keep pushing boundaries and I need a lot of space for that. The sabbatical gave me that space.

While some took classes to learn, others learned in concert with others, like Dan, who said, "It gave me an opportunity to see what other people are doing and spend some time thinking about that and different ways that I might do things or get new ideas." Zach spent time abroad in the lab of a colleague. "I joined his research group and started going to group meetings. I learned a lot from him about a professional attitude and I learned a lot about professional engagement. He taught me so many things."

\section{Professional Relationships}

Like Zach expressed, professional relationships were another key site of learning and professional growth for the faculty members. Whether it was the kind of learning that Dan and Zach discussed above, or simply the space and time to collaborate with others, all of the faculty members in this study shared experiences of reconnecting with peers or meeting new peers that enhanced their sabbatical and contributed to their professional growth.

Grant writing was one specific site of such professional relationship engagement for many of these faculty members. Gordon talked about such relationship engagement related to a colleague at another institution he visited while on sabbatical: "We went ahead and started working together and wrote a few grants. [The sabbatical] gave me the opportunity to get much better at grant writing and practice these skills." Julie also engaged in grant-work with colleagues from other institutions after she met some new collaborators at an international conference. "We made this connection that took that sort of research that I was going to do during the sabbatical in this different direction. I spent a bunch of time working with them on a proposal that ended up getting funded."

For Zach, these professional relationships were important in both of his sabbaticals. While he discussed spending time in the new colleague's lab in his first 
sabbatical, the second sabbatical - once he was promoted to the rank of professor - was very much focused on collaborations:

In both cases, my collaborations changed. Who I worked with and why I worked with them. Out of my first sabbatical it was about wanting to answer different questions and actually interact with different people. That got exacerbated or strengthened in my second sabbatical; meaning, I no longer cared about the questions, per se, but that I wanted to work with interesting people.

There were others, like Ben and Dan, who were excited to make connections with new colleagues at other institutions. Visiting these institutions not only to learn from these new colleagues, but also to create connections that would ultimately be in service to future students and even their home units. Ben explained, "I tried to be an ambassador for our program and university, in forming linkages - research and administrative linkages. The sabbatical enables you to establish real links with people who you would not even know exist."

\section{Agency}

If one adopts Marshall's (2000) definition of agency as "the human capacity... to act intentionally, planfully and reflexively" (p. 11), the faculty members in this study were certainly agentic in how they considered about what, where, and how they engaged in their sabbatical leaves. For all of the faculty members, an initial agentic action as it concerned the sabbatical was the decision to take a half or a whole academic year for their leave. While much of this was dictated by finances - given that LGU pays full salary for one semester of leave and half salary for the entire academic year - a substantial part of this decision rested on the familial obligations or needs of the faculty member. Zach said, "The half year was because my family cannot afford to take a full year at half pay."

In fact, family and balance were common topics in the faculty member's experiences. Jeremy explained, "The number one thing for me in the sabbatical is getting some kind of family balance. My wife looks forward to the sabbatical as much as I do." Ben also pointed out, "It was a family decision. I need to be supportive at home for work-life balance." The same was true for Zach: "I had not parented at the level that I wanted. I wanted a better connection with my kids, which I got during sabbatical."

Regardless of the time or the familial connections of the faculty members, they were all clear in stating that the sabbatical leave provided them with meaningful time to seek out a renewed sense of balance in their lives, to refresh, or provide them with a chance to become reenergized. For Ashley, the sabbatical provided her with a chance "to regroup, take care of myself. I put so much energy into my students. I just needed to give something back to myself." Claire echoed this sentiment, "It allowed me to take some time for personal reflection and nurturing the life part of the work-life balance stuff, which I think was ultimately critical to my success." Three of the faculty members - George, Adia, and Julie - also shared that they used their sabbatical time to schedule surgeries, recover from health-related concerns, or even to battle cancer. George said, "It was fortuitous that I was on leave to have this 
major surgery. There would have been no way that I could have handled my ordinary duties as a faculty person without the sabbatical." Nevertheless, some expressed a sense of guilt over the time they used for themselves - whether for physical or mental health. Adia was one who expressed guilt in her conversation with me quite frequently. She said, "I was so burned out. I was not productive. I had goals for that leave but I didn't accomplish any of them. I felt guilty the whole time." Julie similarly shared, "I had all these plans of what I was going to do but what I ended up doing wasn't exactly what I said I was going to do. At the time I felt just so awful. I was beating myself up. But, in the end, it was a time that led to what I wanted, which was a change in my research and new collaborations."

\section{Commitments}

Quite related to the concept of agency, the faculty members in this study also discussed the decisions they made during their sabbatical to invest in specific commitments in their professional growth and learning. These commitments ranged from a desire to learn more and improve their teaching, take a new direction in their research, as discussed above, but also to their larger discipline. For several of the faculty members, these decisions manifested themselves in opportunities to "say yes" to opportunities and commitments to which they would normally have to "say no." Examples included being available to the media and to give invited talks throughout the world. Ashley provided one such instance: "They were opportunities to connect me with entirely new people and really stepped up the profile of my professional reputation. It would have been harder for me to say yes to some of these opportunities if I hadn't had this space that I did on sabbatical." "I was able to take on a mentee," Sadie shared, "through one of our professional organizations. I wouldn't have been able to have the space to do that without the sabbatical." Claire also explained, "I was able to get involved in a variety of community organizations and issues that I hadn't had the time to contribute to in the way that I wanted previously."

In turn, these commitments also strengthened their commitment to LGU itself. Gordon explained it this way:

The benefit [of the sabbatical] is so astronomical. Our students like us more, they get more opportunities. We retain better faculty. We gain more perspective, build networks. All this made my job better and also more fun. It wasn't the time away, it was the work that was done during that time that made such a big difference.

Indeed, several of the most senior faculty discussed how the sabbatical leave provided them with the space and time to deepen their commitment to LGU through serving in leadership roles upon their return. Sadie explained, "I dearly love my unit. I love my college. I love this university. So whenever I'm asked to step in and do something I have a really hard time saying 'no.' While on sabbatical I could do that and then come back to hop back in." Julie said, "I came back more willing to engage and to take more of a leadership role. I couldn't have done that before. I'm a much better departmental citizen." Adia similarly shared, "I felt renewed enough to come back and resume my chairship. If I hadn't had that, I don't think I would have made 
it. I would have ended up walking away." Jeremy also explained, "Knowing that I'll have the opportunity to prioritize my research, I am more willing to serve the state and take on responsibilities to organizations in the state."

\section{Discussion}

The purpose of this study was to better understand how faculty members at one research institution made sense of their sabbatical experiences in relation to professional growth, per the model of O'Meara and colleagues (O'Meara et al., 2008). In particular, the concepts of learning, agency, professional relationships, and commitments to frame the sabbatical were apropos for this study and these 12 faculty members' experiences. If anything, it was difficult to ascertain where each of these concepts started and stopped in the faculty members' recollections of their sabbatical.

For example, it was evident that all of the faculty members engaged in deep learning during their sabbatical. How and what they learned, however, had as much to do with the colleagues with whom they engaged as it did with the agentic choices they made to do this learning. Similarly, the commitments the faculty felt to their careers, the profession, and to their families strongly dictated the choices they made in where they learned, how they learned, and with whom they learned. In this way, the findings of this study underscore the work of O'Meara et al. (O'Meara et al., 2008) in stating that "these aspects are not mutually exclusive...distinct aspects interact and no doubt influence one another" (p. 26). To be certain, much of the faculty career is integrative in nature, wherein one's teaching does not exist in isolation of the scholarship one conducts or the service in which one engages (Boyer, 1990; Colbeck, 1998). It was therefore unsurprising to hear these faculty members discuss how their sabbaticals entailed a similar interconnectedness of the faculty triumvirate of teaching, research, and service.

The key part of accomplishing all of this, though, was time. The sabbatical provides the faculty member with a benefit of time, whether a semester or a full year (Kang \& Miller, 1999; Miller et al., 2012). Months with "no distractions," a "space to think," and "the chance to focus," were all common refrains in the faculty members' interviews. The sabbatical provided this time and space to think deeply, engage fully, and - in the words of several participants - the opportunity to take risks, to fail, and to pivot to new topics and ideas. The reality well known by most faculty members is that concentrated learning requires time, which is perhaps "the scarcest resource of all" (O'Meara \& Terosky, 2010, p. 48). As such, without the concentrated time provided by the sabbatical, faculty members in this study would not have been able to produce scholarship, remain conversant in their discipline, and bring such benefits to their teaching. Agency and the sabbatical leave are also connected in that - perhaps for the first time in their professional academic careers - these faculty members were able to construct how they would use this time without the external structures of classes, meetings, and other academic-related responsibilities. Nevertheless, scholarly productivity was omnipresent in their recollections of their sabbatical leave, pointing to the constraining forces that academia inserts and that may not allow for true agency (Baez, 2000; Gonzales, 2013) and, for some in this study, 
resulted in feelings of guilt or even shame by pushing back against these constraining forces.

It was also striking how important this time was for the faculty members in realizing balance in their lives, for (re)connecting with their family members, and, for some, taking time for their health. Perhaps just as striking is how little emphasis concepts such as balance and personal growth have received in the empirical literature on sabbatical experiences (Baruch et al., 2014). Such issues of work-life balance strike at the heart of employee job satisfaction and retention (Hagedorn, 2000; McCoy et al., 2013; Wolf-Wendel \& Ward, 2006; Wright et al., 2004) and paint a somewhat bleak picture if these opportunities for balance or caring for health-related concerns only come every five to six years for faculty members like those at LGU. Agency was again at work in these faculty members' sabbatical experiences as they chose to utilize their leaves to not only engage in the scholarly productivity expected of them but also to willingly provide time for themselves and their loved ones. In this way, these faculty members engaged in agentic behaviors that transcended the institution's expectations for this time intended to be purely scholarly in nature (Baez, 2000; Gonzales, 2014).

\section{Implications}

Taken together, the findings from this study point to several implications for policy and practice. Certainly, the faculty members in this study discussed the many positive outcomes that emanated from their sabbaticals, whether that was professional learning, personal growth, or just a chance to recuperate or renew their sense of passion. From this perspective, the sabbatical held both tangible benefits for the institution at which they all worked in regard to their scholarly productivity but also in regard to retention. When one considers the financial investment that a sabbatical entails on behalf of both the employee and the university, not to mention the many years of salary and benefits leading up to the sabbatical itself, productivity and retention are important returns on the investment.

What goes unsaid here, though, is that the experiences of these 12 faculty members all reflected those in mid- to late-career of tenured positions. All 12 of these faculty members had earned tenure and promotion at LGU, thereby able to access the sabbatical leave benefit. Obviously, such a benefit is unavailable to most contingent faculty members (Davidson et al., 2010; Kang \& Miller, 1999; Potter, 2010); in fact, part-time and adjunct faculty tend to be those whose labor replaces faculty on sabbatical leaves (Otto \& Kroth, 2011; Potter, 2010). To be sure, all institutions do not offer the sabbatical leave benefit for even their full-time faculty (Eells \& Hollis, 1962; Kang \& Miller, 1999; Sima, 2000), pointing to the privileged nature of this experience and the participants at LGU.

Given the relatively privileged opportunity that the sabbatical offers, the findings of this study might point to the overarching benefits elicited from the sabbatical not only to the individual faculty member but also to the institutions in which they work and the larger disciplines to which they contribute. In this sense, faculty professional growth (O'Meara et al., 2008) is an apt model to provide for an understanding of the 
professional development needs and choices of faculty members but can also be a key construct for predicting important outcomes to institutions and disciplines, such as faculty retention, engagement, and other tangible outcomes like teaching effectiveness and research productivity (O’Meara \& Terosky, 2010). In other words, sabbatical leaves can be helpful tools for all kinds of faculty at all kinds of institutions to meet many of the institutions' coveted outcomes, including teaching effectiveness, research productivity, and community engagement.

From the perspective of the faculty member who is considering embarking on a sabbatical, implications from this study are also prevalent. Preparing for the sabbatical was something that came up in the interviews with these faculty members, including financial planning to be able to budget for a longer period of time, as well as planning for their scholarly pursuits while on sabbatical. At the same time, being realistic about how much they could get done or should get done was important to balance with family time and rejuvenation. Over planning for the individual faculty member's sabbatical might result in feelings of guilt or anxiety, for example, that do not lend to any of the positive, personal outcomes that were mentioned in this study.

\section{Limitations and Future Research}

This study was an exploratory study that by definition was limited to 12 faculty members at one institutional setting. Future research should consider how various differences make a difference in faculty members' sabbatical experiences. For example, gendered differences. While not a standout aspect of this study - indeed, more of the men faculty discussed how their sabbaticals provided for more opportunities to connect with family than did the women faculty - it is perhaps this "out-of-theordinary" role that these men were able to take on during their sabbatical that would provide fodder for future exploration. The participants in this study were predominantly white and mid-career at a research university, providing limited transferability of findings to more diverse institutional settings. Similarly, racial/ethnic differences as well as the intersecting identities of faculty members are worthy of further exploration in future studies of the sabbatical as it is clear that underrepresented faculty members experience less job satisfaction and more negative working environments than their white counterparts (Baez, 2000; Perna, 2001; Trower, 2009).

Similarly, future research should examine how differences in institutional type and discipline manifest in the sabbatical experiences of faculty. While sparse scholarship exists about the sabbatical, there is even less research focused on differences within and between institutions and disciplines. This study was limited in scope to one institution and only a small number of disciplines. While I was able to interview faculty from several different disciplinary groupings, no clear differences emerged from how they made sense of their sabbatical experiences. Future researchers could examine and compare sabbatical experiences and outcomes by both institutional type and disciplinary groupings.

The nature of the timing of this study is also a point to consider as a limitation to this study and its findings. Namely, the data collection occurred during the 
COVID-19 pandemic at a very uncertain time, both globally and locally, wherein the institution at which this study was situated was facing an uncertain financial future due to unforeseen consequences of the pandemic. While this was not a focus of the study nor of the protocol guiding the interviews, future studies might consider how financial stability of the institution may influence participants' experiences.

The choice of faculty professional growth as a conceptual lens for this study could also be seen as a limitation in that it provides a relatively narrow view of only a particular set of outcomes for the individual faculty member. Future studies should explore how different theoretical and conceptual lenses may more holistically explain the various outcomes and experiences related to the faculty sabbatical.

Finally, future research should also examine the impact of the sabbatical experience upon retention and promotion metrics, including any possible relationship between sabbaticals and applying for promotion to "full" professor as well as the potential impact for other employee groups in the higher education sphere, including staff. Knowing that the sabbatical experience can be gendered and that women in many underrepresented fields experience a lag to promotion or even disparate promotion rates (Gardner \& Blackstone, 2013; Misra et al., 2010; O'Connor et al., 2012), further analysis may be warranted.

Taken together, the faculty experience with sabbatical leaves merits further understanding and study. Much like the faculty in this study who learned from their experiences, there is much more learning yet to realize about this phenomenon.

Data Availability N/A - data are confidential as interviews.

Code Availability N/A

\section{Declarations}

Ethics Approval This study was performed in line with the principles of the Declaration of Helsinki. Approval was granted by the Human Subjects Committee of the University of Maine (April 17, 2020; No. 2020_04_02).

Consent to Participate All participants provided consent to participate per the guidelines of the University of Maine's Human Subjects Committee.

Conflicts of Interest/Competing Interests The author has no relevant financial or nonfinancial interests to disclose.

\section{References}

AAUP. (2009). No refuge: The annual report on the economic status of the profession 2009-10. https:// www.aaup.org/sites/default/files/files/zreport_1.pdf

Academic Senate for California Community Colleges. (2007). Sabbaticals: Benefiting faculty, the institution, and students. https://asccc.org/papers/sabbaticals-benefiting-faculty-institution-and-students American Association of University Professors. (1995). Policy documents and reports (8th ed.). AAUP. Austin, A. E. (2002). Preparing the next generation of faculty: Graduate school as socialization to the academic career. The Journal of Higher Education, 73, 94-121. 
Baez, B. (2000). Race-related service and faculty of color: Conceptualizing critical agency in academe. Higher Education, 39, 363-391.

Baldwin, R. G., \& Blackburn, R. T. (1981). The academic career as a developmental process: Implications for higher education. The Journal of Higher Education, 52(6), 598-614.

Baruch, Y., Dany, F., Pralong, J., Davense, C., Carraher, S. M., Crocitto, M. M., \& Sullivan, S. (2014). A kaleidoscope career perspective on faculty sabbaticals. Career Development International.

Blackburn, R. T., \& Lawrence, J. H. (1995). Faculty at work: Motivation, expectation, satisfaction. Johns Hopkins University Press.

Boyer, E. L. (1990). Scholarship reconsidered: Priorities of the professoriate. Carnegie Foundation for the Advancement of Teaching.

Carnegie Classification of Institutions of Higher Education. (2018). The Carnegie classification of institutions of higher education. https://carnegieclassifications.iu.edu/index.php

Colbeck, C. L. (1998). Merging in a seamless blend: How faculty integrate teaching and research. The Journal of Higher Education, 69, 647-671.

Davidson, O. B., Eden, D., Westman, M., Cohen-Charash, Y., Hammer, L. B., Kluger, A. N., Krausz, M., Maslach, C., O’Driscoll, M., \& Perrewé, P. L. (2010). Sabbatical leave: Who gains and how much? Journal of Applied Psychology, 95(5), 953-964.

Eberle, A. W., \& Thompson, R. E. (1972, 1972). Sabbatical leaves in higher education Student Association of Higher Education.

Eells, W. C. (1962). The origin and early history of sabbatical leave. AAUP Bulletin, 48(3), $253-256$.

Eells, W. C., \& Hollis, E. V. (1962). Sabbatical leave in American higher education: Origin, early history, and current practices. E. U. S. Department of Health, and Welfare. https://files.eric.ed.gov/ fulltext/ED544008.pdf

Erikson, E. H. (1980). Identity and the life cycle. Norton.

Gappa, J. M., Austin, A. E., \& Trice, A. G. (2007). Rethinking faculty work: Higher education's strategic imperative. Jossey-Bass.

Gardner, S. K., \& Blackstone, A. (2013). Putting in your time: Faculty experiences in the process of promotion to full professor. Innovative Higher Education, 38, 411-425.

Gardner, S. K., Jansujwicz, J. S., Hutchins, K., Cline, B., \& Levesque, V. (2014). Socialization to interdisciplinarity: Faculty and student perspectives. Higher Education, 67(3), 255-271.

Gonzales, L. D. (2013). Faculty sensemaking and mission creep: Interrogating institutionalized ways of knowing and doing legitimacy. The Review of Higher Education, 36, 179-209.

Gonzales, L. D. (2014). Framing faculty agency inside striving universities: An application of Bourdieu's theory of practice. The Journal of Higher Education, 85, 193-218.

Hagedorn, L. S. (2000). Conceptualizing faculty job satisfaction: Components, theories, and outcomes. In L. Serra Hagedorn (Ed.), What contributes to job satisfaction among faculty and staff (pp. 5-20). Jossey-Bass.

Hermanowicz, J. C. (1998). The stars are not enough: Scientists-their passions and professions. University of Chicago Press.

Kang, B., \& Miller, M. T. (1999). An overview of the sabbatical leave in higher education: A synopsis of the literature base. (ED 430 471). Retrieved from https://files.eric.ed.gov/fulltext/ED430471.pdf

Kimball, B. A. (1978). The origin of the sabbath and its legacy to the modern sabbatical. The Journal of Higher Education, 49(4), 303-315. https://doi.org/10.2307/1979188

Lattuca, L. R. (2001). Creating interdisciplinarity: Interdisciplinary research and teaching among college and university faculty. Vanderbilt University Press.

Lattuca, L. R. (2002). Learning interdisciplinarity: Sociocultural perspectives on academic work. The Journal of Higher Education, 73(6), 711-739.

Lattuca, L. R. (2005). Faculty work as learning: Insights from theories of cognition. New Directions for Teaching and Learning, 2005(102), 13-21.

Mamiseishvili, K., \& Miller, M. (2010). Faculty sabbatical leaves: Evidence from NSOPF, 1999 and 2004. The Journal of Faculty Development, 24(1), 11-18.

Marsh, H. W., \& Hattie, J. (2002). The relation between research productivity and teaching effectiveness. Journal of Higher Education, 73(5), 603-641.

Marshall, V. (2000, August). Agency, structure, and the life course in the era of reflexive modernization. American Sociological Association Annual Meeting.

McCoy, S. K., Newell, E. E., \& Gardner, S. K. (2013). Seeking balance: The importance of environmental conditions in men and women faculty's well-being. Innovative Higher Education, 38, 309-322. 
Merriam, S. B. (2001). Andragogy and self-directed learning: Pillars of adult learning theory. New Directions for Adult and Continuing Education, 89, 3-13.

Merriam, S. B. (2009). Qualitative research: A guide to design and implementation. Jossey-Bass.

Miller, M., Kang, B., \& Newman, R. E. (2012). A critical examination of sabbatical application policies: Implications for academic leaders. College Quarterly, 15(2), 1-12.

Misra, J., Lundquist, J., Holmes, E., \& Agiomavritis, S. (2010). Associate professors and gendered barriers to advancement. In. University of Massachusetts.

Neumann, A. (2005). Observations: Taking seriously the topic of learning in studies of faculty work and careers. New Directions for Teaching and Learning, 2005(102), 63-83.

Neumann, A. (2009). Professing to learn: Creating tenured lives and careers in the American research university. Johns Hopkins University Press.

O'Connor, A. M., Gahn, S. W., \& Bowen, B. S. (2012). Becoming a professor: An analysis of gender on the promotion of faculty from associate to full professor. International Journal of Gender, Science, and Technology, 4(1), 78-101.

O’Meara, K., Rivera, M., Kuvaeva, A., \& Corrigan, K. (2017). Faculty learning matters: Organizational conditions and contexts that shape faculty learning. Innovative Higher Education.

O’Meara, K., Terosky, A., \& Neumann, A. (2008). Faculty careers and work lives: A professional growth perspective. Jossey-Bass.

O’Meara, K. A., \& Terosky, A. L. (2010). Engendering faculty professional growth. Change, 42(6), 44-51.

Otto, L. R., \& Kroth, M. (2011). An examination of the benefits and costs of sabbatical leave for general higher education, industry, and professional-technical/community college environments. https:// files.eric.ed.gov/fulltext/EJ952051.pdf

Perna, L. W. (2001). Sex and race differences in faculty tenure and promotion. Research in Higher Education, 42, 541-567.

Potter, C. B. (2010, August 5). Who — and how many — paid for your sabbatical this year? Tenured Radical. https://tenured-radical.blogspot.com/2010/05/who-and-how-many-paid-for-your.html

Rosser, V. J. (2004). Faculty members' intentions to leave: A national study on their worklife and satisfaction. Research in Higher Education, 45, 285-309.

Schuster, J. H., \& Finkelstein, M. J. (2006). The American faculty: The restructuring of academic work and careers. The Johns Hopkins University Press.

Sima, C. M. (2000). The role and benefits of the sabbatical leave in faculty development and satisfaction. New Directions for Institutional Research, 2000(105), 67-75.

Sima, C. M., \& Denton, W. E. (1995). Reasons for and products of faculty sabbatical leaves Association for the Study of Higher Education.

Trower, C. A. (2009). Toward a greater understanding of the tenure track for minorities. Change, 41(5), $38-45$.

Wolf-Wendel, L. E., \& Ward, K. (2006). Faculty work and family life: Policy perspectives from different institutional types. In S. J. Bracken, J. K. Allen, \& D. R. Dean (Eds.), The balancing act: Gendered perspectives in faculty roles and work lives (pp. 51-72). Stylus.

Wright, M. C., Howery, C. B., Assar, N., McKinney, K., Kain, E. L., Glass, B., Kramer, L., \& Atkinson, M. (2004). Greedy institutions: The importance of institutional context for teaching in higher education. Teaching Sociology, 32, 144-159.

Xu, Y. J. (2008). Faculty turnover: Discipline-specific attention is warranted. Research in Higher Education, 49, 40-61.

Yin, R. K. (2009). Case study research: Design and methods (4th ed.). Sage.

Zahorski, K. J. (1994). The sabbatical mentor: A practical guide to successful sabbaticals. Anker.

Zhou, Y., \& Volkwein, J. F. (2004). Examining the influences on faculty departure intentions: A comparison of tenured versus nontenured faculty at research universities using NSOPF-99. Research in Higher Education, 45, 139-176.

Publisher's Note Springer Nature remains neutral with regard to jurisdictional claims in published maps and institutional affiliations. 